\title{
Stem Rust Resistance in A-Genome Diploid Relatives of Wheat
}

M. N. Rouse and Y. Jin, United States Department of Agriculture-Agricultural Research Service, Cereal Disease Laboratory, University of Minnesota, St. Paul 55108

\begin{abstract}
Rouse, M. N., and Jin, Y. 2011. Stem rust resistance in A-genome diploid relatives of wheat. Plant Dis. 95:941-944.

Wheat stem rust, caused by Puccinia graminis f. sp. tritici, has been effectively controlled through the use of genetic resistance. P. graminis f. sp. tritici race TTKSK (Ug99) possesses virulence to many resistance genes that have been used in wheat breeding worldwide. One strategy to aid breeders in developing resistant cultivars is to utilize resistance genes transferred from wild relatives to wheat. Stem rust resistance genes have previously been introgressed from Triticum monococcum to wheat. In order to identify additional resistance genes, we screened 1,061 accessions of T. monococcum and 205 accessions of T. urartu against race TTKSK and four additional $P$. graminis $\mathrm{f} . \mathrm{sp}$.

of the accessions (78.7\% of T. monococcum and $93.0 \%$ of T. urartu) were resistant to $P$. graminis f. sp. tritici race TTKSK, with infection types ranging from 0 to $2+$. Among these resistant accessions, $55 \mathrm{~T}$. monococcum accessions (6.4\% of the total) were also resistant to the other four races. Associations of resistance in T. monococcum germplasm to different races indicated the presence of genes conferring resistance to multiple races. Comparing the observed infection type patterns to the expected patterns of known genes indicated that previously uncharacterized genes for resistance to race TTKSK exist in both T. monococcum and T. urartu.
\end{abstract} tritici races: TTTTF, TRTTF, QFCSC, and MCCFC. A high frequency
Puccinia graminis f. sp. tritici, the causal agent of wheat stem rust, has caused major yield losses throughout history. Since 1955, severe stem rust epidemics have been effectively controlled in the United States and Canada through the deployment of resistant cultivars. In Uganda in 1999, a race of $P$. graminis f. sp. tritici (Ug99) was characterized that is virulent to Sr31 and many other stem rust resistance genes (15). Ug99 is identified as race TTKSK based on the North American stem rust nomenclature (8). $P$. graminis f. sp. tritici race TTKSK has subsequently spread throughout Eastern Africa (20), Yemen, and Iran (14). In 2006, a variant of race TTKSK was found in Kenya that possesses virulence to $\operatorname{Sr} 24$ (race TTKST; 8). In 2007, a variant with virulence to $\operatorname{Sr} 36$, designated as race TTTSK, was detected (9). The distributions of the variants of race TTKSK are unique and $\mathrm{Sr} 24$ and $S r 36$ could be effectively used where virulence is not currently present. However, the rapid detection and emergence of the variants should caution the deployment of $\mathrm{Sr} 24$ or $\mathrm{Sr} 36$ alone.

Preliminary tests conducted in Kenya suggested that nearly all of the current wheat cultivars grown in Asia are susceptible to race TTKSK (19). Jin and Singh (6) evaluated 450 cultivars and advanced breeding lines from the United States and found $84 \%$ of the hard red spring wheat, $52 \%$ of the hard red winter wheat, and $73 \%$ of the soft winter wheat to be susceptible to race TTKSK at the seedling stage. Moreover, many of the resistant lines possessed Sr24 and Sr36 $(7,9)$, to which races TTKST and TTTSK are virulent, respectively. Similarly, Fetch (2) found the majority of the Canadian wheat cultivars to be susceptible to race TTKSK. Several genes have been identified to be effective against race TTKSK (7). Most of these effective genes were derived from alien relatives of wheat and many have not been used in breeding due to linkage drag (19).

Corresponding author: Y. Jin, E-mail: yuejin@umn.edu

* The $e$-Xtra logo stands for "electronic extra" and indicates that two supplementary tables are available online.

Accepted for publication 24 February 2011.

doi:10.1094/PDIS-04-10-0260

This article is in the public domain and not copyrightable. It may be freely reprinted with customary crediting of the source. The American Phytopathological Society, 2011.
One of the strategies to develop cultivars resistant to race TTKSK is to identify and introgress additional resistance from the wild relatives of wheat. Triticum urartu is the A-genome progenitor of wheat and T. monococcum is closely related to T. urartu; therefore, introgressions from these species to hexaploid wheat can be made with relative ease $(10,23)$. Accessions of $T$. monococcum were screened with multiple $P$. graminis f. sp. tritici races to postulate the presence of resistance genes (23). Three stem rust resistance genes ( $S r 21, S r 22$, and $S r 35)$ have been identified and transferred from $T$. monococcum $(3,10,11,22,23)$. Races of $P$. graminis f. sp. tritici with virulence to $S r 21$ are common worldwide, except in Australia (5). Virulence to $\mathrm{Sr} 22$ was not identified in a worldwide survey published in 1992 (5) but such races were reported in Israel in 1971 (3). Virulence to Sr35 was identified in North and South America, Africa, and southern Asia (5). Sr22 and Sr35 have been shown to be effective to race TTKSK at both the seedling and adult plant stages (7). The effectiveness of $S r 21$ in hexaploid wheat to race TTKSK was considered uncertain (7). The objective of this study was to identify race TTKSK resistance in $T$. urartu and $T$. monococcum germplasm.

\section{Materials and Methods}

Accessions (205 of T. urartu and 1,062 of T. monococcum) were obtained from the United States Department of Agriculture National Small Grains Collection (Aberdeen, ID) in 2007. The $T$. monococcum germplasm was divided into 848 accessions listed as T. monococcum subsp. aegilopoides (wild einkorn, synonymous $T$. aegilopoides, and T. boeoticum) and 214 accessions listed as $T$. monococcum subsp. monococcum (cultivated einkorn). One accession classified as T. monococcum subsp. aegilopoides, PI 306526, is actually $T$. dicoccoides and was not included in the analyses. Accessions were screened with five races of $P$. graminis $\mathrm{f}$. $\mathrm{sp}$. tritici (Table 1). Isolate 04KEN156 has previously been identified as race TTKSK $(6,7,24)$ based on the North American differentials for $P$. graminis f. sp. tritici $(8,16,17)$. Isolates of races TTTTF and TRTTF were used in this study because of their virulence to genes to which race TTKSK is avirulent (Table 1). Isolates of races QFCSC and MCCFC were selected because of their ability to differentiate among T. monococcum resistance genes $\mathrm{Sr} 21$ and Sr35 when used in combination with the other races.

Urediniospores of stem rust isolates in gelatin capsules stored at $-80^{\circ} \mathrm{C}$ were heat shocked at $45^{\circ} \mathrm{C}$ for $15 \mathrm{~min}$, and placed in a rehydration chamber maintained at $80 \%$ relative humidity by a $\mathrm{KOH}$ 
solution for 2 to $4 \mathrm{~h}$ (18). Procedures for inoculation, incubation, and disease assessment were performed as described previously (7). Susceptible controls ('Chinese Spring' [CI 14108] and 'Rusty' [PI 639869]) were inoculated with each race along with the test entries.

Disease reactions were classified according to Stakman et al. (21). Infection types (ITs) $0, ;, 1$, and 2 were considered low ITs characteristic of host resistance and pathogen avirulence. ITs 3 and 4 were considered high and such accessions were classified as susceptible. When low and high ITs were present on the same leaf, the reaction was considered resistant (12). In each assay, 6 to 10 plants were evaluated. When plants segregated for resistance within an accession, the accession was considered heterogeneous. An accession was considered resistant to the five races combined if the reaction to each of the five races was resistant. In total, 107 randomly selected $T$. monococcum accessions (10\% of the total) were screened with races TTKSK, TTTTF, and TRTTF a second time to test the repeatability of scoring rust reactions. The frequency of consistent classification of resistance was used as a measure of repeatability.

Frequencies of reactions (resistant, susceptible, and heterogeneous) to each of the five $P$. graminis f. sp. tritici races and the combined reaction to all five races were calculated for $T$. urartu and $T$. monococcum. We calculated $\chi^{2}$ values in order to test the assumption of independence of reaction among the five races. Frequencies of rust reactions within the two T. monococcum subspecies were calculated. For T. urartu, $91 \%$ of the accessions were from either Turkey or Lebanon. Previous studies indicated that $T$. urartu accessions from Turkey formed a distinct phylogenetic clade from accessions collected in Lebanon $(4,13)$. Therefore, we also calculated the frequency of resistant accessions from Turkey and from Lebanon, separately, and $\chi^{2}$ values were also calculated to test for deviation in percent resistance between the wild and cultivated forms of T. monococcum and the Turkey and Lebanon collections of T. urartu.

We postulated the presence of $S r 21, S r 22$, and $S r 35$ in T. monococcum accessions based upon known and observed reactions of the $P$. graminis f. sp. tritici races on monogenic and digenic lines $(11,23)$. For $S r 21$ postulations, we considered race TTKSK ITs of 3- or 3 as indicative of $\mathrm{Sr} 21$ when resistance was also observed to race MCCFC. This deviation from the traditional classification of resistance and susceptibility was made because intermediate ITs
(23-) have been previously reported for avirulent cultures to $\mathrm{Sr} 21$ (12) and the reaction of race TTKSK specifically to $S r 21$ was described as not certain (7). For both T. monococcum subsp. aegilopoides and T. monococcum subsp. monococcum, we calculated the frequency of accessions postulated to possess known genes.

\section{Results}

Screening data are available online. The frequency and number of T. monococcum and T. urartu accessions resistant, susceptible, and heterogeneous to the five races and the races combined are displayed in Tables 2 and 3, respectively. A high frequency of the $T$. monococcum and T. urartu accessions were resistant to race TTKSK. Relatively few $T$. monococcum accessions were resistant to races TRTTF and TTTTF, and no $T$. urartu accessions were resistant to these two races. We found a higher frequency of accessions resistant or heterogeneous to races TRTTF and TTTTF in $T$. monococcum subsp. monococcum relative to $T$. monococcum subsp. aegilopoides (Tables 2 and 4). In contrast, a higher frequency of $T$. monococcum subsp. aegilopoides accessions was resistant to races TTKSK and MCCFC. T. urartu accessions collected in Lebanon were more often resistant to races TTKSK and MCCFC than those collected in Turkey (Tables 3 and 4).

Associations of resistance to different races were significant as measured by the pairwise comparisons, except for the TRTTFMCCFC and TTTTF-MCCFC race comparisons (Table 5). All significant associations of resistance were positive. This means that T. monococcum accessions resistant to one race were resistant to other races more often than expected under the assumption that resistance to the five races is independent. For T. urartu, associations were not significant (Table 5), indicating that independent race-specific genes likely confer resistance to races TTKSK, MCCFC, and QFCSC.

The ITs of three lines with known T. monococcum stem rust resistance genes are given in Table 6. Gene postulations for the tested accessions are listed in Supplementary Table 1. Some accessions displayed IT patterns that could not be explained by the previously characterized resistance genes. The frequency of postulated known genes is displayed in Table 7.

Out of 297 pairwise comparisons of ITs, 14 comparisons were inconsistent, resulting in a repeatability of $95.28 \%$. Of those 14 comparisons, 9 were misclassified for $P$. graminis f. sp. tritici TTKSK with a $2+3$ IT in one replication and a $3-$ or 3 IT in the

Table 1. Races of Puccinia graminis f. sp. tritici used to screen Triticum monococcum germplasm

\begin{tabular}{lll}
\hline Race & Isolate & \multicolumn{1}{c}{ Virulence or avirulence formula } \\
\hline TRTTF & 06YEM34-1 & $5,6,7 \mathrm{~b}, 9 \mathrm{a}, 9 \mathrm{~b}, 9 \mathrm{~d}, 9 \mathrm{e}, 9 \mathrm{~g}, 10,11,17,21,30,36,38, \mathrm{McN}, \mathrm{Tmp} / 8 \mathrm{a}, 22,24,31,35$ \\
TTKSK & 04KEN156/04 & $5,6,7 \mathrm{~b}, 8 \mathrm{a}, 9 \mathrm{a}, 9 \mathrm{~b}, 9 \mathrm{~d}, 9 \mathrm{e}, 9 \mathrm{~g}, 10,11,17,30,31,38, \mathrm{McN} / 22,24,35,36, \mathrm{Tmp}$ \\
TTTTF & 01MN84A-1-2 & $5,6,7 \mathrm{~b}, 8 \mathrm{a}, 9 \mathrm{a}, 9 \mathrm{~b}, 9 \mathrm{~d}, 9 \mathrm{e}, 9 \mathrm{~g}, 10,11,17,21,30,36, \mathrm{McN}, \mathrm{Tmp} / 22,24,31,35,38$ \\
QFCSC & 03ND76C & $5,8 \mathrm{a}, 9 \mathrm{a}, 9 \mathrm{~d}, 9 \mathrm{~g}, 10,17,21,35, \mathrm{McN} / 6,7 \mathrm{~b}, 9 \mathrm{e}, 9 \mathrm{~b}, 11,22,24,30,31,36,38, \mathrm{Tmp}$ \\
MCCFC & 59KS19 & $5,7 \mathrm{~b}, 9 \mathrm{~g}, 10,17,35, \mathrm{McN}, \mathrm{Tmp} / 6,8 \mathrm{a}, 9 \mathrm{a}, 9 \mathrm{~d}, 9 \mathrm{e}, 9 \mathrm{~b}, 11,21,22,24,30,31,36,38$ \\
\hline
\end{tabular}

a $\mathrm{Sr} 21$ is not included in this table for TTKSK.

Table 2. Number (and frequency) of Triticum monococcum accessions resistant, susceptible, and heterogeneous to five stem rust races and the combined reaction to the five races

\begin{tabular}{|c|c|c|c|c|}
\hline Accessions, race & Total & Number resistant (\%) & Number susceptible (\%) & Number heterogeneous (\%) \\
\hline \multicolumn{5}{|c|}{ T. monococсит subsp. aegilopoides } \\
\hline TRTTF & 804 & $62(7.7)$ & $724(90.0)$ & $18(2.2)$ \\
\hline TTKSK & 805 & $662(82.2)$ & $109(13.5)$ & $34(4.2)$ \\
\hline TTTTF & 808 & $55(6.8)$ & $741(91.7)$ & $12(1.5)$ \\
\hline QFCSC & 702 & $165(23.5)$ & $523(74.5)$ & $14(2.0)$ \\
\hline MCCFC & 712 & $649(91.1)$ & $42(5.9)$ & $21(2.9)$ \\
\hline Combined & 643 & $38(5.9)$ & $594(92.4)$ & $11(1.7)$ \\
\hline \multicolumn{5}{|c|}{ T. monococcum subsp. monococcum } \\
\hline TRTTF & 213 & $37(17.4)$ & $161(75.6)$ & $15(7.0)$ \\
\hline TTKSK & 214 & $140(65.4)$ & $52(24.3)$ & $22(10.3)$ \\
\hline TTTTF & 213 & $40(18.8)$ & $157(73.7)$ & $16(7.5)$ \\
\hline QFCSC & 213 & $45(21.1)$ & $162(76.1)$ & $6(2.8)$ \\
\hline MCCFC & 213 & $182(85.4)$ & $25(11.7)$ & $6(2.8)$ \\
\hline Combined & 211 & $17(8.1)$ & $186(88.2)$ & $8(3.8)$ \\
\hline
\end{tabular}


other replication. This variability is likely due to $\operatorname{Sr} 21$ and was accounted for in the gene postulations (ITs 3- or 3 to TTKSK were considered as resistant interactions for gene postulation). Excluding this variability, five comparisons were misclassified $\mathbf{( 9 8 . 3 2 \%}$ repeatability). For these five misclassified comparisons, the ITs of the replications classified as resistant were $2+3,23+Z, 2+3 / 123 Z$, or $; 3+Z$, indicating that misclassifications only occurred when the IT of the resistant replication was relatively high. The IT data used for the repeatability test is available online as Supplementary Table 2.

\section{Discussion}

Accession PI 428170 (G2919) was used by P. L Dyck to introgress Sr35 into hexaploid wheat (11). PI 428170 and other accessions postulated to possess $\mathrm{Sr} 35$ displayed a unique pattern of ITs: 0 to TRTTF, 0 to TTKSK, X- LIF (mesothetic with low infection frequency) to TTTTF, 4 to QFCSC, and 4 or ;1 to MCCFC (depending on the presence or absence of $S r 21$ ). We postulated the presence of $S r 35$ in 21 accessions of T. monococcum subsp. monococcum, and no accessions of T. monococcum subsp. aegilopoides
(Table 7). The higher frequency of resistance to races TTKSK and MCCFC in T. monococcum subsp. aegilopoides is likely due to a higher frequency of accessions carrying $S r 21$ in this subspecies.

A higher frequency of $T$. urartu accessions from Lebanon were resistant to races TTKSK and MCCFC compared with accessions from Turkey. This difference might be a result of the divergent evolutionary history known in this species from these two countries $(4,13)$. Identification of geographical areas where a higher frequency of collected landraces were resistant to stem rust has been used to prioritize further screening (1). If this strategy is used for identifying stem rust resistance in T. urartu, screening of additional accessions from Lebanon, not Turkey, should be prioritized. However, relatively few T. urartu accessions were screened in this study and additional screening of accessions could be beneficial, regardless of geographic origin.

Close associations for resistance to different races in $T$. monococcum accessions suggest that resistance is usually effective against multiple races, when it is present. A high frequency of accessions exhibited resistance to races TTKSK and MCCFC. This

Table 3. Number (and frequency) of Triticum urartu accessions resistant, susceptible, and heterogeneous to five stem rust races and the combined reaction to the five races

\begin{tabular}{lcccc}
\hline Accessions, race & Total & Number resistant $(\%)$ & Number susceptible (\%) & Number heterogeneous $(\%)$ \\
\hline Lebanon, T. urartu & & & & \\
TRTTF & 88 & $0(0)$ & $88(100)$ & $0(0)$ \\
TTKSK & 87 & $86(98.9)$ & $0(0)$ & $1(1.1)$ \\
TTTTF & 92 & $0(0)$ & $92(100)$ & $0(0)$ \\
QFCSC & 87 & $1(1.1)$ & $86(98.9)$ & $1(1.2)$ \\
MCCFC & 86 & $48(55.8)$ & $37(43.0)$ & $0(0)$ \\
Combined & 78 & $0(0)$ & $78(100)$ & $0(0)$ \\
Turkey, . urartu & 81 & $0(0)$ & $81(100)$ & $5(6.2)$ \\
TRTTF & 81 & $72(88.9)$ & $4(4.9)$ & $0(0)$ \\
TTKSK & 88 & $0(0)$ & $88(100)$ & $1(1.2)$ \\
TTTTF & 81 & $2(2.5)$ & $78(96.3)$ & $2(2.5)$ \\
QFCSC & 79 & $1(1.3)$ & $76(96.2)$ & $0(0)$ \\
MCCFC & 71 & $0(0)$ & & \\
Combined & & & & \\
\hline
\end{tabular}

Table 4. Association of rust reactions between the two subspecies of Triticum monococcum and two countries of origin of T. urartu

\begin{tabular}{|c|c|c|c|c|c|c|}
\hline \multirow{2}{*}{$\frac{\text { Species }}{\text { T. monocoсcum }}$} & \multicolumn{2}{|c|}{ Association between } & \multirow{2}{*}{$\begin{array}{c}\text { Race } \\
\text { TRTTF }\end{array}$} & \multirow{2}{*}{$\frac{\chi^{2}}{20.38}$} & \multirow{2}{*}{$\frac{\text { Association type }^{\mathbf{a}}}{\text { WS/CR }}$} & \multirow{2}{*}{$\frac{P \text { value }}{1.41 \mathrm{E}-4}$} \\
\hline & Wild & Cultivated & & & & \\
\hline & Wild & Cultivated & TTKSK & 19.92 & $\mathrm{WR} / \mathrm{CS}$ & $1.76 \mathrm{E}-4$ \\
\hline & Wild & Cultivated & TTTTF & 32.75 & WS/CR & 3.64 E-7 \\
\hline & Wild & Cultivated & QFCSC & 0.45 & $\mathrm{~ns}$ & 0.93 \\
\hline & Wild & Cultivated & MCCFC & 8.30 & $\mathrm{WR} / \mathrm{CS}$ & 0.04 \\
\hline & Wild & Cultivated & Combined & 2.30 & ns & 0.51 \\
\hline \multirow[t]{3}{*}{ T. urartu } & Lebanon & Turkey & TTKSK & 8.15 & LR/TS & 0.043 \\
\hline & Lebanon & Turkey & QFCSC & 0.80 & ns & 0.85 \\
\hline & Lebanon & Turkey & MCCFC & 62.78 & LR/TS & $1.50 \mathrm{E}-13$ \\
\hline
\end{tabular}

${ }^{a}$ For significant associations $(P<0.05)$, the association type between classes (W, wild; C, cultivated; L, Lebanon; and T, Turkey) and either resistance (R) or susceptibility (S) are indicated; ns indicates a nonsignificant association.

Table 5. Association of rust reactions among the five races in pairwise comparisons as measured by $\chi^{2}$ values and probability

\begin{tabular}{|c|c|c|c|c|c|}
\hline \multirow{2}{*}{$\frac{\text { Species }}{\text { T. monococcum }}$} & \multicolumn{2}{|c|}{ Association between races } & \multirow{2}{*}{$\frac{\chi^{2}}{15.90}$} & \multirow{2}{*}{$\frac{\text { Association type }^{\mathrm{a}}}{+}$} & \multirow{2}{*}{$\frac{P \text { value }}{0.0012}$} \\
\hline & TRTTF & TTKSK & & & \\
\hline & TRTTF & TTTTF & 554.10 & + & 8.99 E-120 \\
\hline & TRTTF & QFCSC & 163.35 & + & 3.46 E-35 \\
\hline & TRTTF & MCCFC & 1.70 & ns & 0.64 \\
\hline & TTKSK & TTTTF & 17.79 & + & 4.86 E-4 \\
\hline & TTKSK & QFCSC & 15.38 & + & 0.0015 \\
\hline & TTKSK & MCCFC & 149.23 & + & 3.87 E-32 \\
\hline & TTTTF & QFCSC & 131.90 & + & $2.11 \mathrm{E}-28$ \\
\hline & TTTTF & MCCFC & 1.65 & $\mathrm{~ns}$ & 0.65 \\
\hline & QFCSC & MCCFC & 15.22 & + & 0.0016 \\
\hline \multirow[t]{3}{*}{ T. urartu } & TTKSK & QFCSC & 0.28 & $\mathrm{~ns}$ & 0.96 \\
\hline & TTKSK & MCCFC & 2.29 & ns & 0.51 \\
\hline & QFCSC & MCCFC & 4.35 & ns & 0.23 \\
\hline
\end{tabular}

\footnotetext{
${ }^{\text {a }}$ For significant associations $(P<0.05),+$ indicates a positive association among resistant accessions, - indicates a negative association among resistant
} accessions, and ns indicates a nonsignificant association. 
Table 6. Infection type patterns of lines containing previously characterized Triticum monococcum stem rust resistance genes to stem rust races used in this study

\begin{tabular}{llcccccc}
\hline & \multicolumn{5}{c}{ Race } \\
\cline { 3 - 6 } Line & Background & TRTTF & TTKSK & TTTTF & QFCSC & MCCFC & Genes \\
\hline PI 10474 & Diploid & $3+$ & $; 1$ & $3+$ & $3+$ & $; 1$ & Sr21 \\
PI 428170 & Diploid & $0 ;$ & 0 & X-LIF & 4 & $; 1$ & Sr35+ Sr21 \\
PI 660256 & Hexaploid & $; 2-$ & $2-$ & $2-$ & $2-$ & 1 & $S r 22$ \\
\hline
\end{tabular}

${ }^{a} \mathrm{X}$ indicates a mesothetic infection type with both compatible and incompatible interactions and LIF indicates low infection frequency.

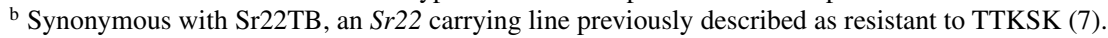

Table 7. Frequency of postulated stem rust resistance genes in Triticum monococcum germplasm

\begin{tabular}{lrcccccc}
\hline & & \multicolumn{5}{c}{ Number of accessions (\%) } \\
\cline { 3 - 7 } Accessions & Total & Sr21 & Sr22 & Sr35 & Sr21+Sr35 & Susceptible & Unknown \\
\hline T. monococcum subsp. aegilopoides & 847 & $673(79.5)$ & $52(6.1)$ & $0(0)$ & $0(0)$ & $23(2.7)$ & $99(11.7)$ \\
T. monococcum subsp. monococcum & 214 & $128(59.8)$ & $15(7.0)$ & $6(2.8)$ & $15(7.0)$ & $15(7.0)$ & $35(16.4)$ \\
Total T. monococcum & 1,061 & $801(75.5)$ & $67(6.3)$ & $6(0.6)$ & $15(1.4)$ & $38(3.6)$ & $134(12.6)$ \\
\hline
\end{tabular}

resistance may be attributed to $S r 21$. Similarly, The (23) found the majority of T. monococcum accessions screened to possess $\operatorname{Sr} 21$. P. graminis f. sp. tritici race TTKSK is classified as virulent to $\operatorname{Sr} 21$; however, experimental evidence is currently inconclusive (7). Though TTKSK is known to produce moderately high ITs (3 or higher) on $\mathrm{Sr} 21$ of some hexaploid wheat lines, a low IT may be observed at the seedling stage in diploids. Several T. monococcum accessions displayed IT patterns that could not be explained by $S r 21, S r 22$, or $S r 35$ alone or in combination.

T. urartu has not been used as a source for the introgression of stem rust resistance genes. Therefore, the stem rust resistance observed is likely due to new genes. Accessions resistant to TTKSK were often susceptible to other races used in this study. Because we did not observe significant associations of resistance between the races, resistance to races TTKSK, QFCSC, and MCCFC is most likely conferred by single race-specific resistance genes.

Major gene resistance introgressed from wild relatives of wheat has been an effective source of genetic resistance to stem rust. Uncharacterized genes resistant to race TTKSK introgressed into adapted germplasm will aid breeders in developing resistant cultivars. Screening the T. monococcum and T. urartu germplasm in this study resulted in the identification of uncharacterized genes or alleles that provide resistance to race TTKSK. Genetic studies have been initiated to determine the number and allelic relationships of uncharacterized resistance genes, validate our gene postulations, and facilitate the mapping of $\mathrm{Sr} 21, \mathrm{Sr} 22, \mathrm{Sr} 35$, and uncharacterized genes in diploid backgrounds.

\section{Acknowledgments}

We thank H. Bockelman, United States Department of Agriculture-Agricultural Research Service, National Small Grains Collection, Aberdeen, ID, for distributing T. urartu and T. monococcum seed; R. A. McIntosh for providing valuable insight into gene postulations in T. monococcum; and L. Wanschura, S. Gale, and several student technicians whose technical support made this research possible.

\section{Literature Cited}

1. Bonman, J. M., Bockelman, H. E., Jin, Y., Hijmans, R. J., and Gironella, A. I. N.. 2007. Geographic distribution of stem rust resistance in wheat landraces. Crop Sci. 47:1955-1963.

2. Fetch, T., Jr. 2007. Virulence of stem rust race TTKS on Canadian wheat cultivars. Can. J. Plant Pathol. 29:441.

3. Gerechter-Amitai, Z. K., Wahl, I., Vardi, A., and Zohary, D. 1971. Transfer of stem rust seedling resistance from wild diploid einkorn to tetraploid durum wheat by means of a triploid hybrid bridge. Euphytica 20:281-285.

4. Heun, M., Haldorsen, S., and Vollan, K. 2008. Reassessing domestication events in the Near East: Einkorn and Triticum urartu. Genome 51:444-451.

5. Huerta-Espino, J. 1992. Analysis of wheat leaf and stem rust virulence on a worldwide basis. Ph.D. thesis, University of Minnesota, St. Paul.

6. Jin., Y., and Singh, R. P. 2006. Resistance in U.S. wheat to recent Eastern African isolates of Puccinia graminis f. sp. tritici with virulence to resistance gene Sr31. Plant Dis. 90:476-480.
7. Jin, Y., Singh, R. P., Ward, R. W., Wanyera, R., Kinyua, M., Njau, P., Fetch, T., Pretorius, Z. A., and Yahyaoui, A. 2007. Characterization of seedling infection types and adult plant infection responses of monogenic $\mathrm{Sr}$ gene lines to race TTKS of Puccinia graminis f. sp. tritici. Plant Dis. 91:1096-1099.

8. Jin, Y., Szabo, L. J., Pretorius, Z. A., Singh, R. P., Ward, R. W., and Fetch, T., Jr. 2008. Detection of virulence to resistance gene $\mathrm{Sr} 24$ within race TTKS of Puccinia graminis f. sp. tritici. Plant Dis. 92:923-926.

9. Jin, Y., Szabo, L. J., Rouse, M. N., Fetch, T., Jr., Pretorius, Z. A., Wanyera, R., and Njau, P. 2009. Detection of virulence to resistance gene Sr36 within the TTKS race lineage of Puccinia graminis f. sp. tritici. Plant Dis. 93:367370.

10. Kerber, E. R., and Dyck, P. L. 1973. Inheritance of stem rust resistance transferred from diploid wheat (Triticum monococcum) to tetraploid and hexaploid wheat and chromosome location of the gene involved. Can. J. Genet. Cytol. 15:397-409.

11. McIntosh, R. A., Dyck, P. L., The, T. T., Cusick, J., and Milne, D. L. 1984. Cytogenetical studies in wheat XIII. Sr35-a third gene from Triticum monococcum for resistance to Puccinia graminis tritici. Z. Pflanzenzuecht. 92:1-14.

12. McIntosh, R. A., Wellings, C. R., and Park, R. F. 1995. Wheat Rusts: An Atlas of Resistance Genes. CSIRO, Australia.

13. Moghaddam, M., Ehdaie, B., and Waines, J. G. 2000. Genetic diversity in populations of wild diploid wheat Triticum urartu Tum. ex. Gandil. revealed by isozyme markers. Genet. Resour. Crop Evol. 47:323-334.

14. Nazari, K., Mafi, M., Yahyaoui, A., Singh, R. P., and Park, R. F. 2009 Detection of wheat stem rust (Puccinia graminis f. sp. tritici) race TTKSK (Ug99) in Iran. Plant Dis. 93:317.

15. Pretorius, Z. A., Singh, R. P., Wagoire, W. W., and Payne, T. S. 2000. Detection of virulence to wheat stem rust resistance gene Sr31 in Puccinia graminis f. sp. tritici in Uganda. Plant Dis. 84:203.

16. Roelfs, A. P., Long, D. L., and Roberts, J. J. 1993. Races of Puccinia graminis in the United States during 1990. Plant Dis. 77:125-128.

17. Roelfs, A. P., and Martens, J. W. 1988. An international system of nomenclature for Puccinia graminis f. sp. tritici. Phytopathology 78:526-533.

18. Rowell, J. B. 1984. Controlled infection by Puccinia graminis f. sp. tritici under artificial conditions. Pages 292-332 in: The Cereal Rusts, Vol. 1. Origins, Specificity, Structure, and Physiology. W. R. Bushnell and A. P. Roelfs, eds. Academic Press, Orlando, FL.

19. Singh, R. P., Hodson, D. P., Huerta-Espino, J., Jin, Y., Njau, P., Wanyera, R. Herrera-Foessel, S. A., and Ward, R. 2008. Will stem rust destroy the world's wheat crop? Adv. Agron. 98:271-309.

20. Singh, R. P., Hodson, D. P., Jin, Y., Huerta-Espino, J., Kinyua, M. G., Wanyera, R., Njau, P., and Ward, R. 2006. Current status, likely migration and strategies to mitigate the threat to wheat production from race Ug99 (TTKS) of stem rust pathogen. CAB Reviews: Perspectives in Agriculture, Veterinary Science, Nutrition and Natural Resources, 1, No. 054.

21. Stakman, E. C., Stewart, D. M., and Loegering, W. Q. 1962. Identification of physiologic races of Puccinia graminis var. tritici. U. S. Dep. Agric. Agric. Res. Serv. E-617.

22. The, T. T. 1973. Chromosome location of genes conditioning stem rust resistance transferred from diploid to hexaploid wheat. Nat. New Biol. 241:256.

23. The, T. T. 1973. Transference of resistance to stem rust from Triticum monococcum L. to hexaploid wheat. Ph.D. thesis, The University of Sydney, Australia.

24. Wanyera, R., Kinyua, M. G., Jin, Y., and Singh, R. P. 2006. The spread of stem rust caused by Puccinia graminis f. sp. tritici, with virulence on $S r 31$ in wheat in Eastern Africa. Plant Dis. 90:113. 